\title{
DENSIDAD DE MILITANCIA PARTIDISTA, APROBACIÓN PRESIDENCIAL Y EL DESEMPEÑO ELECTORAL DE LA DERECHA EN CHILE (2010-2014)
}

\author{
Hugo Jofré \\ Universidad de Chile \\ Patricio Navia \\ New York University / Universidad Diego Portales
}

\begin{abstract}
Resumen: A diferencia de los gobiernos de la Concertación (19902010), la formación del gabinete durante el cuatrienio de la Alianza (2010-2014) tuvo menor Índice de Densidad Partidista (IDP), indicador que los autores proponen para medir el nivel de involucramiento partidista de un equipo de gobierno. Con datos de militancia del gabinete del gobierno de Piñera y del primer gobierno de Bachelet (2006-2010), se muestra que el IDP está positivamente correlacionado con la aprobación presidencial y con los resultados en las elecciones al final del periodo. La incapacidad del gobierno de Piñera para
\end{abstract}

Hugo Jofré. Administrador público de la Universidad de Chile. Estudiante de magíster en políticas públicas en la Facultad de Economía y Negocios de la Universidad de Chile. Email: hugojofrerodriguez@gmail.com.

Patricio Navia. PhD en ciencias políticas por la Universidad de Nueva York. Profesor en global studies en el Liberal Studies Program y profesor adjunto del Centro de Estudios Latinoamericanos y del Caribe de la Universidad de Nueva York. Profesor en la Escuela de Ciencias Políticas de la Universidad Diego Portales. Email: patricio.navia@.nyu.edu.

Los autores agradecen a Carlos Palacios, Bastián González-Bustamante, Hugo Eduardo Herrera y a los dos revisores anónimos de Estudios Públicos por sus valiosos comentarios y sugerencias. Este artículo se inscribe en los proyectos del Fondecyt regular (n. $\left.{ }^{\circ} 1171051\right)$ y del Centro de Estudios de Conflicto y Cohesión Social (Conicyt/Fondap n. $\left.{ }^{\circ} 15130009\right)$ 
reflejar el peso de los partidos de su coalición en la composición del gabinete contribuyó, de acuerdo a este trabajo, a explicar las fluctuaciones en la aprobación presidencial y la derrota de su coalición en las elecciones presidenciales y legislativas al final de su periodo.

Palabras Clave: voto económico, voto retrospectivo, partidos de derecha, Chile.

RECIBIDO: agosto 2016; ACEPTADO: enero 2017.

\section{DENSITY OF PARTY MILITANCY, PRESIDENTIAL APPROVAL AND THE ELECTORAL PERFORMANCE OF THE RIGHT IN CHILE (2010-2014)}

ABSTRACT: Unlike what happened under Concertación governments (1990-2010), the formation of the cabinet under the Alianza government (2010-2014) had a lower Partisanship Density Index (IDP), an indicator proposed by the authors to measure the level of participation in party activities in a government cabinet. With party militancy data from ministers and undersecretaries of the Piñera (2010-2014) and Michelle Bachelet (2006-2010) administrations, it is shown that the PDI is positively correlated with presidential approval and electoral results at the end of the period. The incapacity of the Pinera government to adequately reflect the weight of his coalition's parties in his cabinet contributed, under the authors perspective, to the fluctuations in presidential approval and to his coalition's defeat in the presidential and legislative elections at the end of the term.

KEYwords: economic vote, retrospective vote, rightwing parties, Chile.

ReCEIVED: August 2016; ACCEPTED: January 2017.

\section{INTRODUCCIÓN}

E $n$ Chile, la coalición gobernante de la Alianza fue derrotada en 2013 en condiciones económicas favorables. A diferencia de los gobiernos de la Concertación, que conformaron sus gabinetes fundamentalmente con militantes de partidos, el gobierno de Sebastián Piñera (2010-2014) tuvo mayor presencia de independientes en su gabinete. Argumentamos que la capacidad del gobierno de incorporar exitosamente a los partidos de su coalición en el gabinete contribuye a explicar tanto la aprobación del gobierno como los resultados electorales al final del periodo. La baja densidad partidista en la administración de Piñera contribuyó a sus bajos niveles de aprobación y su derrota en las elecciones presidenciales y legislativas en 2013. 
Discutimos primero la teoría sobre conformación de gabinetes, especulamos sobre sus efectos electorales contrastándola con la teoría del voto económico y voto de clase. Luego definimos lo que entendemos por éxito de un gobierno: aprobación presidencial y desempeño electoral en las contiendas presidencial y legislativa al fin del periodo. Formalizamos nuestra hipótesis asociando la densidad de militancia partidista al éxito del gobierno. Luego, repasamos la historia política de los partidos de derecha, enfatizando la permanente valoración por los independientes vinculados al mundo de los negocios y por los tecnócratas por sobre los políticos. Discutimos cómo ese rechazo hacia la política se evidenció al comienzo del gobierno de Piñera con la composición de su gabinete. Proponemos una forma de medir la densidad de militancia partidista, y la aplicamos a los gobiernos de Bachelet (2006-2010) y Piñera. Luego mostramos que cuando el gobierno de Piñera aumentó su densidad de militancia, mejoró su aprobación presidencial. Concluimos asociando la densidad de militancia partidista con la aprobación presidencial durante el cuatrienio de Piñera y con los resultados en la elección presidencial y legislativa en 2013.

\section{CÓMO MEDIR EL ÉXITO DE UN GOBIERNO}

Los modelos dominantes que dan cuenta del desempeño electoral incorporan variables de largo, mediano y corto plazo (Bartels 2011). Las variables de largo plazo enfatizan características permanentes de las personas, como su religión o condición de clase. Siguiendo esta lógica, independientemente del desempeño de un gobierno, la gente siempre votaría de forma similar. Pero como hay varianza en los patrones de votación, las variables de largo plazo son insuficientes para explicar las preferencias de la gente. Las variables de mediano plazo enfatizan la socialización política de las personas, y permiten mayor varianza. El mal desempeño de un gobierno pudiera constituir un elemento de socialización política que eventualmente lleve a la gente a castigarlo. Las variables de corto plazo enfatizan el desempeño del gobierno saliente y las expectativas sobre las alternativas que tienen los electores como determinantes de sus preferencias. Las explicaciones sobre las preferencias de la gente a menudo incluyen elementos de largo, mediano y corto plazo. Entre estos últimos, que son los que mejor dan cuenta de la 
varianza entre una elección y otra, tienden a prevalecer las explicaciones asociadas con el desempeño económico. Pero cuando este último es positivo y los resultados electorales para el gobierno son adversos, necesariamente las variables explicativas de corto plazo deben incorporar consideraciones no económicas, para dar cuenta de por qué, bajo condiciones económicas favorables, el gobierno tiene un pobre desempeño electoral.

Según Ferejohn (1986), la mejor herramienta de presión de los electores es el castigo a los representantes electos que incumplen sus promesas. Al modificar el tradicional modelo del votante mediano - que supone electores que deciden a partir de las promesas que hacen los candidatos-, Ferejohn (1986) argumenta que los votantes hacen una evaluación retrospectiva. Cuando el candidato ganador cumple lo que prometió, el votante lo premia con su voto. Ahora bien, porque las promesas de campaña no siempre pueden ser materializadas y porque los electores tienen dificultades para saber si las promesas se cumplieron, el voto retrospectivo se asocia con la evaluación subjetiva que hacen los votantes de las condiciones económicas, ya sea considerando "el desempeño económico del país (evaluación sociotrópica) o el propio (egotrópica)" (Navia y Osorio 2015, 10).

Los modelos de voto económico, así, ayudan a entender las razones de los votantes retrospectivos para premiar o castigar a los gobiernos salientes a partir del desempeño de la economía a nivel macro y micro (Duch y Stevenson 2008). Si bien abundan los estudios que analizan el efecto de variables económicas - como la inflación y el crecimiento- sobre los resultados de una elección, la forma en que las personas procesan los resultados económicos, tomando en cuenta sus predisposiciones e inclinaciones políticas, ha permitido incorporar consideraciones de mediano y largo plazo, como la socialización política y la posición de clase, en las decisiones sobre el voto de las personas.

Downs (1957) plantea que en un contexto de información imperfecta y costosa, al ser incapaces de reunir toda la información necesaria para tomar decisiones que maximicen su utilidad, los ciudadanos recurren a las "ideologías de partido" para bajar los costos de información. Así, aunque tengan similar evaluación sobre las mismas condiciones económicas, un votante de derecha será menos proclive que uno de izquierda a mantener en el poder a un presidente izquierdista. 
Los votantes también pueden premiar a un gobierno de coalición a partir de su capacidad para dar gobernabilidad o mantener el orden (Ferejohn 1986). Si esto es cierto, la composición y desempeño del gabinete puede utilizarse como un indicador que influye en la evaluación retrospectiva que hacen las personas de los gobiernos. Cuando un gobierno de coalición refleja adecuadamente su diversidad en el gabinete y los partidos miembros se disciplinan gracias a la composición del gabinete, los electores presumiblemente premiarán los resultados positivos de esa disciplina y cohesión en la gobernabilidad del país.

\section{LA COMPOSICIÓN DEL GABINETE COMO DETERMINANTE DEL ÉXITO DE UN GOBIERNO}

En sus trabajos sobre asignación de puestos en el gabinete, Laver y Shepsle $(1990 ; 1996)$ plantean la tesis del cabinet allocation portfolio. Al asignar adecuadamente puestos en el gabinete a los distintos partidos de la coalición, el gobierno asegura la lealtad de esos partidos. Laver y Shepsle (1996) plantean la formación del gobierno en democracias parlamentarias en un modelo de tres etapas: el partido mayoritario propone un gabinete con una distribución de cupos entre los partidos miembros (propuesta), los partidos miembros pueden vetar la propuesta si no satisface sus expectativas y, finalmente, la propuesta es sometida a votación del parlamento para buscar el apoyo de la mayoría legislativa que permita gobernar. El objetivo es un equilibrium cabinet estable y duradero (Laver y Shepsle 1996, 61).

Este planteamiento responde a las dinámicas de la democracia parlamentaria, pero existe suficiente evidencia de que esta lógica aplica también a sistemas presidenciales multipartidistas (Figueiredo y Limongi 2000). De hecho, en sistemas presidenciales, aunque sus poderes y atribuciones varían en distintos países, el presidente es el formateur del gabinete (Alemán y Tsebelis 2012). Los gabinetes ministeriales constituyen el principal espacio de incidencia para diseñar y ejecutar las políticas públicas, por lo que los actores políticos buscan conquistarlo y ejercer desde ahí su influencia (Olivares et al. 2015). Ya que no todos los ministerios poseen igual influencia (Laver y Hunt 1992), la distribución de cupos en el gabinete plantea desafíos para balancear las expectativas de los partidos de la coalición con los intereses del ejecutivo. 
Amorim Neto (2006), al centrar su análisis en cómo los presidentes conforman su gabinete, plantea que las "expectativas sobre el desempeño del gobierno (...) se centran en la habilidad del presidente para alcanzar sus objetivos de políticas públicas" (Amorim Neto 2006, 416). Para lograrlo, los mandatarios cuentan con dos estrategias: el proceso legislativo (statutes strategy) o a través de prerrogativas unilaterales del ejecutivo que no requieren pasar por el poder legislativo (executive prerogative strategy). Amorim Neto señala que cuando el presidente opta por la estrategia del proceso legislativo, nombra más ministros con militancia política, asignando cupos de forma más proporcional al peso de cada partido en el Congreso. En cambio, al optar por la estrategia de las atribuciones exclusivas del ejecutivo, se nombra un gabinete con menos militancia y de forma menos proporcional. Amorim Neto postula que "sólo presidentes que cuenten con partidos que posean un considerable número de escaños en la legislatura y sean ideológicamente de inclinación de centro serán propensos a implementar políticas mediante la estrategia legislativa (statutes) y, por tanto, a nombrar un gabinete de mayoría legislativa y a seleccionar ministros con militancia política (2006, 436). Junto con esto, "si un presidente tiene la alternativa constitucional de emitir decretos de ley y ostenta poder de veto extensivo, existe la tentación de copar su gabinete principalmente con tecnócratas y amigotes y distribuir cupos de una forma menos que justa" (Amorim Neto 2006, 437). Con todo, los presidentes se ven condicionados por el entramado institucional, pero en ese contexto la conformación del gabinete resulta clave para lograr sus objetivos y en el éxito del gobierno.

El caso chileno es de un sistema presidencial fuerte con presidentes moderados (Siavelis 2000). El Congreso ejerce capacidad de veto sobre las iniciativas del ejecutivo y se ha consolidado en una posición negociadora poderosa (Aninat et al. 2011). Siavelis identifica ciertas herramientas que usan los presidentes para mantener la disciplina de su coalición. Una de esas herramientas es el "cuoteo", que Siavelis (2009) define como la distribución de cargos ministeriales y de subsecretarías de manera ecuánime (lo que Laver y Sheplse llamarían cabinet allocation portfolio). El "cuoteo" permitió que los partidos se sintieran representados, incentivando la disciplina en el oficialismo (Siavelis 2009, 8). El gabinete ministerial vincula a los partidos con el gobierno y la designación ministerial puede entenderse como un elemento de cooperación entre el gobierno 
y los partidos políticos que lo apoyan (Avendaño y Dávila 2012, 90). Además, hay variables que explican el ingreso y la permanencia de agentes en ciertos cargos estratégicos del gabinete. Palacios y Jofré (2016) plantean que la confianza entre el presidente y los agentes resultaría fundamental para el reclutamiento, donde la participación en el comando de campaña sería decisivo. Con todo, los autores aseguran que "los presidentes tienden a construir sus centros de gobierno con unas élites en las cuales, básicamente, puedan confiar" (Palacios y Jofré 2016, 116).

Otras instituciones informales para la asignación de cupos en la administración pública (Carey y Siavelis 2003) "refuerzan la confianza al asegurar la entrada de los partidos en la adopción de decisiones gubernamentales" (Siavelis 2009, 8). Entre éstas, destaca una que se produce por los incentivos del sistema electoral binominal y que indujo a los gobiernos de la Concertación a nombrar candidatos derrotados en las elecciones legislativas en puestos del gabinete (Carey y Siavelis 2003). Siguiendo a Siavelis, un proceso erróneo en la conformación de los gabinetes ministeriales habría repercutido negativamente en la sobrevivencia de la coalición.

Siguiendo a Amorim Neto (2006), dado el sistema fuertemente presidencialista chileno que, no obstante, limita sus prerrogativas unilaterales legislativas, los presidentes utilizan la estrategia del proceso legislativo (statutes strategy), por lo que una buena relación con los partidos políticos de la coalición - y en especial con sus contingentes en el Congreso - resulta esencial para el éxito del gobierno. Si los electores evalúan al gobierno retrospectivamente por su desempeño político - $-\mathrm{y}$ no sólo por consideraciones económicas - la capacidad del gobierno de mantener la disciplina y unidad de su coalición redundará sobre una gestión exitosa, lo que a su vez explicará también tanto la aprobación del presidente como el resultado electoral en las elecciones al final del periodo.

\section{LA TENSIÓN ENTRE POLÍTICOS DE CARRERA Y TECNÓCRATAS EN LA COMPOSICIÓN DEL GABINETE}

Al nombrar a su gabinete, junto con tener en cuenta la necesidad de dar representación acorde a su peso electoral o político a los distintos partidos de la coalición, la complejidad de los desafíos del Estado exige 
también dotar a las burocracias con herramientas técnicas para resolver las demandas de la ciudadanía (aunque resulte difícil diferenciar las decisiones técnicas de las políticas) (Grindle 1977). La incorporación de tecnócratas al gabinete parece producir resultados positivos. Tanto para el caso chileno como latinoamericano, los gobiernos que tienen una mayor presencia de tecnócratas e independientes en sus gabinetes tienden a generar más reformas (Altman y Castiglioni 2009).

Como los presidentes pueden formar sus equipos con líderes que poseen experiencia partidista o capacidad tecnocrática, ya se trate de militantes o independientes, las lógicas de reclutamiento de los miembros del gabinete resultan esenciales para explicar por qué distintos gobiernos forman gabinetes con combinaciones diferentes de militantes e independientes. Las lógicas de reclutamiento y selección de los agentes que han integrado los gabinetes desde el retorno de la democracia en Chile muestran distintas trayectorias dentro de los elencos ministeriales. Joignant (2011) centra su análisis en los tipos y especies de capitales que ostentan dichos agentes al momento de asumir sus carteras. La taxonomía sugerida por el autor está compuesta por tres grupos de agentes: los tecnócratas, los technopols y los dirigentes de partido. Cada grupo de agente constituye la "expresión de un tipo particular de capital que los separa y singulariza" (Joignant 2011, 53).

Al describir a los tecnócratas, Joignant señala que pueden poseer tanto capital tecnocrático pragmático — que representa a aquel tecnócrata independiente sin vinculación política alguna- como capital tecnocrático político, que representa a individuos con habilidades técnicas reconocidas, pero atributos políticos de baja intensidad (como la militancia partidista). Al caracterizar a los tecnócratas, otra literatura los define como "decision makers en los niveles superiores de la administración de un gobierno con alto nivel de educación formal (doctorado o candidato a doctor en economía) y sin experiencia política (sin militancia)" (Dávila 2011, 36). Al mencionado tecnócrata independiente, Dávila (2011) lo denomina "tecnócrata puro" y lo diferencia de los técnicos, dado que estos últimos "son expertos bajo la dirección de otras élites, mientras que los tecnócratas son actores que tienen acceso a decisiones que van más allá de su área de experticia y que generalmente han sido monopolio de los políticos" (Dávila 2011, 26).

La confluencia de credenciales académicas y experticia técnica constituye un mecanismo de legitimación potente para la incorporación 
a los espacios de poder (Joignant 2011; Delamaza 2011). Los technopols - concepto acuñado por Domínguez (1997) y que identifica a individuos que reúnen experiencia política partidaria y experticia técnica de alto nivel - poseen recursos técnicos, como credenciales académicas, y recursos políticos, reflejados en la ocupación previa de espacios de poder partidario (Joignant 2012). Al describir el fenómeno de los technopols, Domínguez (1997) señala que este tipo de agente busca crear su propio poder de forma independiente, buscando extender su influencia en la toma de decisiones. La sugerencia de que "no son marionetas de otros políticos" (Domínguez 1997, 5) supone que los technopols también buscan competir con los políticos por espacios de influencia en el gobierno.

Como no todos los ministros suponen un mismo perfil - reconociéndose, por ejemplo, un predominio tecnocrático en el Ministerio de Hacienda en América Latina (Silva 2010a)_, la distribución de puestos en el gabinete supone balancear adecuadamente los intereses de los partidos, las necesidades políticas y técnicas del gobierno y las ambiciones personales de los miembros del gabinete. Cuando el gobierno no logra un balance adecuado, le resulta más difícil hacer avanzar su agenda legislativa y ser exitoso en las dimensiones que aquí analizamos: aprobación presidencial y elecciones presidenciales y legislativas al final del periodo.

En Chile, ya que los technopols han sido responsables de las reformas neoliberales de la dictadura de Pinochet, y la posterior consolidación democrática (Silva 2010b), su presencia en los gabinetes en el periodo post 1990 explica en parte la estabilidad de políticas públicas (González-Bustamante 2013). Con todo, la presencia de technopols no minimizó el peso de los partidos durante los gobiernos de la centroizquierdista Concertación. La militancia política fue clave para el reclutamiento de ministros y de otros cargos de confianza, incluidos los technopols (González-Bustamante 2013). De hecho, la participación de independientes - technopols o no- en los gabinetes ministeriales fue marginal en gobiernos de la Concertación (Olivares et al. 2015). En cambio, el gobierno de la Alianza (2010-2014) privilegió conformar su gabinete con un gran número de independientes (Silva 2010b; Dávila 2011). Esto ha llevado a varios a comparar al gobierno de Piñera con el llamado "gobierno de los gerentes" de Jorge Alessandri (1958-1964). Al 
respecto, Silva señala: "Las comparaciones que se han hecho entre el gobierno de Piñera y el gobierno de Jorge Alessandri no sólo iban dirigidas a subrayar el componente tecno-gerencial que lo caracteriza, sino también al hecho de que al final Alessandri se vio forzado a abandonar su proyecto tecnocrático y retomar un camino más cercano a los partidos políticos. En otras palabras, el vaticinio de algunos es que tarde o temprano Piñera también se vería obligado a ir en busca del apoyo partidario para poder afianzar su gobierno y asegurar los necesarios apoyos parlamentarios" (Silva 2010b, 255).

Como el technopol, el dirigente de partido exhibe también dos tipos de capital, aunque de otro orden: el capital militante, marcado por una vida de servicio en un partido y que da paso al hombre de partido, y el capital político oligárquico, marcado por los cargos nacionales de los partidos, que lo convierte en un político profesional. Joignant señala que lo que hace a los hombres de partido un grupo particular es "su exclusiva condición de homo politicus, carente de 'hibridación' (a diferencia de los technopols), de la que fluye una forma profesional de competencia política en el sentido de Weber: un tipo ideal de agente que vive de y para la política (o para el partido)" (Joignant 2011, 55).

La taxonomía presentada por Joignant permite precisar las habilidades y competencias de ambos grupos. Cada tipo de agente actuará de forma reconocible, uniéndolos entre sus pares y diferenciándolos de otros grupos de agentes. Además, la forma de relacionarse con otros grupos será diferente; la relación con partidos y la lealtad hacia la coalición, también. De ahí que, además de que inherentemente existe un conflicto entre los tecnócratas - o technopols - y los dirigentes de partido, los efectos de esa tensión pueden repercutir en el desempeño del gobierno en su conjunto.

\section{CASO DE ESTUDIO Y METODOLOGÍA}

En nuestro caso de estudio, atribuimos a la composición del gabinete un efecto sobre el desempeño del gobierno y sobre la evaluación que la gente hace de ese desempeño, que se materializa en aprobación presidencial y en los resultados electorales al final del periodo. Para ello, comparamos la forma en que el presidente Piñera asignó los cupos en el gabinete a dirigentes de partidos e independientes, con lo que 
ocurrió en el gabinete del gobierno que lo precedió. Nuestra variable independiente es la densidad partidista. Sugerimos que, a mayor densidad partidista, mayores opciones de desarrollar un gobierno exitoso.

Construimos un Índice de Densidad Partidista (IDP) compuesto por cinco condiciones dicotómicas: la militancia partidista, haber presentado una candidatura anterior, ostentar el cargo de concejal o alcalde previamente, ostentar el cargo de legislador previamente y haber ejercido como miembro de la directiva nacional de un partido político. Estos cinco criterios permiten distinguir el nivel de involucramiento partidista de los agentes, independientemente de sus capacidades técnicas. Aquellos agentes con mayor involucramiento político tendrán más posibilidades de ser militantes, haber sido candidatos o dirigentes o haber ocupado cargos de representación popular. Así, independientemente de sus habilidades técnicas, este indicador nos permitirá identificar a los miembros del gabinete con trayectoria de militancia partidista.

El índice tiene valores en un rango de 0 a 1 . Todas las condiciones tienen un valor de 0,2 , a excepción de ostentar cargos de concejal o alcalde previamente, que valen 0,1 y 0,2 , respectivamente, contabilizándose el cargo más alto. La condición de ostentar el cargo de legislador vale 0,4. Para alguien que tuvo más de un cargo de elección popular, sólo contabilizamos el cargo más alto. Así, un ministro que militaba en un partido, tuvo una candidatura anterior (pero no ganó) y ejerció como parte de una directiva tiene un IDP de 0,6. A su vez, un militante que ha sido dirigente partidario y además ha sido alcalde, tiene un IDP de 0,8 , mientras que un militante que fue electo senador y ha sido dirigente del partido tiene un IDP de 1,0. Nuestro objetivo es ir más allá de sólo la militancia formal en un partido para poder entender la densidad de la militancia que poseían las personas que ocuparon cargos de ministros y subsecretarios en los gobiernos de Bachelet y Piñera.

Calculamos el IDP para las 52 personas que ocuparon el cargo de ministro y las 53 personas que sirvieron como subsecretarios en el gobierno de Piñera. Hicimos lo mismo con las 43 y 58 personas que, respectivamente, sirvieron como ministros y subsecretarios en la administración de Bachelet. Contabilizamos a cada individuo en cada cargo que ejerció al menos por cinco meses durante un año. Por ejemplo, Andrés Chadwick ingresó al gabinete de Piñera como ministro secretario general de gobierno, pero luego fue ministro del interior, por lo que se con- 
tabiliza dos veces en el gabinete, y su IDP es 1,0 (en tanto es militante de la UDI, ha sido dirigente de partido, candidato y ha sido legislador).

Si bien creemos que sería útil considerar también a las personas que ejercieron como intendentes, gobernadores, embajadores, jefes de servicios y directores de las empresas públicas, nuestro ejercicio representa una propuesta metodológica cuya validez empírica la evaluamos con datos de los cargos políticos más importantes de un gobierno. A su vez, si bien resulta interesante estudiar la trayectoria política de los miembros del gabinete, nuestro objetivo no es analizar la carrera política o la ambición política de los ministros, sino entender cómo la densidad de militancia partidista afecta el desempeño del gobierno.

El cuadro 1 muestra datos descriptivos del IDP para los gobiernos de Bachelet y Piñera. A nivel de ministros, el IDP fue en promedio de 0,31 para Bachelet y 0,26 para Piñera. El número de ministros con IDP igual a cero — sin militancia partidista, sin candidatura anterior, sin ostentar el cargo de legislador, concejal o alcalde previamente, y sin haber ejercido en la directiva nacional de partido - en el gobierno de Piñera fue de 26 (50 por ciento), mientras que en el gobierno de Bachelet fue de 3 ( 7 por ciento).

De los 52 ministros de Piñera, hay 17 con IDP superior a 0,4, es decir, que cumplían con dos o más criterios. De ellos, 6 fueron parte del primer gabinete: Lavín, Galilea, Parot, Hinzpeter, von Baer y Ravinet (cuya militancia y desempeño anterior habían ocurrido como militante de la Democracia Cristiana en gobiernos de la Concertación). Los otros 11 fueron ministros que se incorporaron más tarde o que fueron designados en otros puestos del gabinete. En el caso de Bachelet, la mitad de sus ministros cumplía con dos o más criterios. La moda en el gabinete de Bachelet fue de 0,20 y en el de Piñera fue de 0. La máxima en ambos gobiernos es de 1,0.

La situación de los subsecretarios es similar a la de los ministros en ambos gobiernos. El IDP de los subsecretarios de Bachelet fue en promedio de 0,25 frente al 0,21 de Piñera. El número de subsecretarios con cero IDP en el gobierno de Bachelet fue de 7 (12 por ciento), mientras que en el gobierno de Piñera fue de 30 (54,5 por ciento), superior porcentualmente a lo observado entre los ministros de Piñera. La mediana de IDP para el gobierno de Bachelet fue de 0,20 y para el de Piñera fue de 0 . La moda fue de 0,2 y 0 , respectivamente. La máxima en ambos 
gobiernos fue de 1,0 y la mínima de 0 . La cantidad de subsecretarios con IDP de 0 en el gobierno de Piñera superó a la de los ministros.

Cuadro 1. ÍNDICE DE DENSIDAD PARTIDISTA (IDP) EN LOS GABINETES DE BACHELET (2006-2010) Y PIÑERA (2010-2014)

\begin{tabular}{lll}
\hline & Bachelet & Piñera \\
\hline Promedio & \multicolumn{2}{c}{ Ministros } \\
Mediana & 0,31 & 0,26 \\
Moda & 0,20 & 0,10 \\
Máxima & 0,20 & 0,00 \\
Mínima & 1,0 & 1,0 \\
Número de ministros con O IDP & 0,00 & 0,00 \\
Número total de ministros & 3 & 26 \\
\hline & 43 & 52 \\
\hline Promedio & \multicolumn{2}{c}{ Subsecretarios } \\
Mediana & 0,25 & 0,21 \\
Moda & 0,20 & 0,00 \\
Máxima & 0,20 & 0,00 \\
Mínima & 1,0 & 1,0 \\
Número de subsecretarios con O IDP & 0,00 & 0,00 \\
Número total de subsecretarios & 7 & 30 \\
\hline
\end{tabular}

Fuente: Autores con datos recopilados de diversas fuentes de acceso público.

Nuestra variable dependiente es el éxito del gobierno. Definimos tres criterios para éxito: si la aprobación presidencial supera el 50 por ciento como promedio en el periodo, si la coalición gobernante ganó las elecciones presidenciales al final del periodo y si esta coalición obtuvo la primera mayoría en las elecciones legislativas al término del periodo presidencial. Estos criterios son presentados de forma dicotómica. Para ejemplificar el análisis, lo aplicamos a los gobiernos de Aylwin (1990-1994), Frei (1994-2000), Lagos (2000-2006), Bachelet (20062010) y Piñera (2010-2014). El cuadro 2 muestra la evaluación de esos gobiernos en cada criterio. El gobierno de Piñera no cumple con ningún criterio que define éxito. Formalmente, nuestra hipótesis es que a mayor 
IDP, mayor éxito del gobierno, medido en las tres dimensiones discutidas anteriormente.

Cuadro 2. CRITERIOS PARA EVALUAR ÉXITO DE LOS GOBIERNOS DE CHILE, 19902014

\begin{tabular}{lcccc}
\hline Presidente & $\begin{array}{c}\text { Apro- } \\
\text { bación } \\
\text { presiden- } \\
\text { cial sobre } \\
50 \%\end{array}$ & $\begin{array}{c}\text { Coalición ganó } \\
\text { elección pre- } \\
\text { sidencial al fin } \\
\text { del mandato }\end{array}$ & $\begin{array}{c}\text { Coalición } \\
\text { ganó } \\
\text { elecciones } \\
\text { legislativas al } \\
\text { fin del periodo }\end{array}$ & $\begin{array}{c}\text { Grado de } \\
\text { éxito } \\
\text { (Suma de } \\
\text { valores "Si") }\end{array}$ \\
\hline Aylwin (1990-94) & Si & Si & Si & 3 \\
Frei (1994-2000) & No & Si & Si & 2 \\
Lagos (2000-2006) & Si & Si & Si & 3 \\
Bachelet (2006-2010) & Si & No & Si & 2 \\
Piñera (2010-2014) & No & No & No & 0 \\
\hline
\end{tabular}

Fuente: Elaboración de los autores.

\section{LA DERECHA Y LA TECNOCRACIA ANTES DE PINOCHET}

Las dificultades vividas por el gobierno de Piñera encarnan los traumas históricos de la derecha, incluido el recelo hacia la actividad partidista y los conflictos entre las colectividades. Los partidos Liberal (PL) y Conservador (PCO) fueron los primeros esfuerzos por institucionalizar a la derecha chilena (Gamboa et al. 2013). La cercanía con la Iglesia determinaba la adhesión partidista (Correa 2011). Ambos partidos adoptaron el capitalismo, además del anticomunismo y el rechazo al activismo sindicalista, pero el PCO fue fuertemente clerical. Por su parte, el PL y sus militantes se encontraban entre la indiferencia religiosa o el anticlericalismo, lo que se tradujo en una concepción pluralista.

En la elección de 1920, el rechazo del PCO y PL a Arturo Alessandri Palma retrata la incapacidad de la derecha para "ser fuerza modernizadora y para lograr 'cortejar' a los partidos intermedios dominantes" (Moulian y Torres 1988, 34). Al fin del segundo periodo de Alessandri (1932-1938), su ex ministro de Hacienda, Gustavo Ross, cayó derrotado en la elección presidencial. La visión política de Ross se caracterizaba 
por un carácter tecnocrático y autoritario, y era presentado como independiente y casi apolítico (Moulian y Torres 1988).

En plena crisis, en la elección presidencial de 1942, el PCO y parte del PL apoyaron al ex militar Carlos Ibáñez, aunque dirigentes del PL como Alessandri Palma adhirieron al candidato del Frente Popular, Juan Antonio Ríos, quien triunfó con el 55 por ciento de los votos. El periodo posterior a 1942 fue de desorden en la derecha (Urbina y Ortúzar 2012). Pero el 23,4 por ciento alcanzado por el PCO sumado al 18,4 por ciento del PL en las legislativas de 1945 hicieron pensar que, con candidato único, la derecha ganaría las presidenciales de 1946.

Esa elección obligó a una definición programática entre la opción capitalista liberal y el fervor socialcristiano. El PL y el PCO convocaron a una convención para definir a su candidato. Eduardo Cruz-Coke, senador y ex ministro de salud de Alessandri, era el candidato del PCO. El PL criticaba el distanciamiento del capitalismo y el carácter sectario y totalizante del discurso de Cruz-Coke, lo que contrastaba con la opción moderada de Fernando Alessandri y su capitalismo liberal. Incapaz de llegar a un acuerdo, la derecha se presentó con dos candidatos: CruzCoke (29,8 por ciento) y Fernando Alessandri (27,4 por ciento), lo que facilitó el triunfo del radical Gabriel González Videla (40,2 por ciento).

Durante el gobierno de González Videla, se produjo un distanciamiento entre radicales y comunistas, lo que ayudó al ingreso del PL y PCO al gobierno. González Videla nombró como ministro de Hacienda al presidente de la Confederación de la Producción y del Comercio (CPC), Jorge Alessandri Rodríguez, en 1947. En paralelo, en 1949 se produjo un quiebre en el PCO, cuya estructura era controlada por los socialcristianos, pero su representación parlamentaria era ejercida mayoritariamente por conservadores tradicionalistas. El principal hito de este quiebre fue la renuncia de la juventud del PCO, liderada por Eduardo Frei Montalva, que dio origen a la Falange Nacional, la que a su vez posteriormente se convertiría en la Democracia Cristiana (PDC).

Fuera del gobierno, Jorge Alessandri se consolidó como defensor del modelo de economía capitalista. El partido Conservador Tradicionalista (PCT) y el PL optaron por el capitalismo liberal, desprendiéndose del socialcristianismo. Desde la CPC, Alessandri fue su vocero. Representando al PL en 1957, Alessandri ganó un escaño en el Senado. Su triunfo en la elección presidencial de 1958 se convirtió en un punto de 
inflexión en la derecha. Con Alessandri Rodríguez, nació el concepto de independiente de derecha, arraigado hasta hoy.

Alessandri tenía un sentir negativo respecto a los partidos políticos (Correa 2011; Guzmán 2008; Boeninger 2014). Para él, los partidos constituían un lastre, por lo que su campaña y su gabinete estuvieron en manos de ingenieros y empresarios. Este último fue caracterizado como el "gobierno de los gerentes". Boeninger (2014) afirma que Alessandri fue un "precursor sólo parcial" de la liberalización de los mercados, ya que el modelo de sustitución de importaciones era aún dominante y el empresariado seguía una estrategia proteccionista dependiente del Estado.

Inicialmente, la implementación del programa de Alessandri logró controlar la inflación e incentivar las exportaciones. Pero en 1961, producto de una crisis en la balanza de pagos, se generó el fracaso del "gobierno de los gerentes". La asepsia política tuvo consecuencias negativas:

Los partidos de derecha y, en general, los partidarios del gobierno de Alessandri ni siquiera fueron capaces de levantar una candidatura presidencial el año 1964 y terminaron apoyando incondicionalmente a Eduardo Frei Montalva. Al año siguiente, en la elección parlamentaria fueron literalmente borrados del mapa, quedando reducidos a una mínima expresión en el Congreso Nacional. (Allamand y Cubillos 2010, 25)

Así, la crisis del sector se profundizó con el apoyo de la derecha a la candidatura del demócrata cristiano Frei Montalva en 1964, cuando "la actuación culposa y pesimista, sumada al personalismo, un pragmatismo timorato y temeroso y las peleas pequeñas llevaron prácticamente a la destrucción de la derecha" (Urbina y Ortúzar 2012, 26). En las elecciones de 1965, el PL y PCO pasaron de 45 a 9 diputados, lo que obligó a comenzar una nueva etapa para la derecha (Huneeus 1998; Gamboa et al. 2013). Los dos partidos de derecha no tuvieron otra alternativa que, en 1966, agruparse en el Partido Nacional (PN). El intenso periodo entre 1966 y 1973 es caracterizado por Boeninger (2014) como uno lleno de derrotas y temores para la derecha, producto de la amenaza al derecho de propiedad que significó la reforma agraria y la radicalización del escenario político. 


\section{LA DERECHA Y LA TECNOCRACIA EN DICTADURA}

Hasta 1973, la derecha y sus dirigentes se "sentían herederos de una brillante tradición de legalidad, civismo y progreso" (Correa 2011, 55-56). Pero, a partir del golpe, la disolución del PN permitió la aparición de nuevas fuerzas políticas en la derecha. El Movimiento Gremial (MG) fue fundado por Jaime Guzmán en 1966 (Huneeus 1973; 1998; Guzmán 2008). El gremialismo tenía una fuerte orientación católica, un fuerte anticomunismo y una desconfianza hacia la democracia representativa. Valorando la tecnocracia sobre la política, Guzmán (2008) criticó a los partidos políticos que apoyaban al gobierno de Alessandri mientras que resaltó las condiciones personales y valentía de Alessandri. Además, destacó que la fallida candidatura presidencial de Alessandri en 1970 se produjo sin la participación de partidos políticos.

La propuesta de Guzmán constituye la síntesis más "elaborada, coherente y efectiva del pensamiento conservador chileno" (Cristi 2011, 20). Guzmán buscaba equilibrar los conceptos de libertad y autoridad, aparentemente contradictorios, tanto con la democracia (vista como una forma de gobierno meramente instrumental, sin valor moral intrínseco) como con la realidad política que experimenta Chile hacia el final de la dictadura de Pinochet (Cristi 2011, 23). Guzmán diferenciaba el rol de las agrupaciones intermedias y el rol de los partidos y las ideologías políticas (Guzmán 2008, 48). Urbina y Ortúzar (2012) describen la importancia de Guzmán a partir de la construcción de un camino teórico y político que busca compatibilizar la inspiración cristiana, la economía de mercado y un marcado sentido del orden.

En dictadura, Guzmán incentivó a gremialistas a incorporarse al gobierno (Huneeus 1998; 2016). La UDI se convirtió en el brazo político de los adherentes de Pinochet y se vinculó con los denominados Chicago Boys. Esta “díada” constituye el principal anclaje de la derecha con el régimen militar y la tecnocracia. Los gremialistas y los Chicago Boys no corresponden a grupos distintos, ya que "el equipo económico no era neutral políticamente, pues eran gremialistas" (Huneeus 1998, 145). La Junta Militar buscaba tecnocratizar la toma de decisiones, ya que creían fundamental convencer a la población de la incompetencia de la "política" (la democracia) para enfrentar problemas públicos (Silva 2010b). Los Chicago Boys se convirtieron en los principales "ideó- 
logos del régimen militar, pues trataron de justificar la coexistencia del autoritarismo político con el liberalismo económico" (Silva 2010b, 161).

Los gremialistas desarrollaron una sintonía con Pinochet debido a que tanto su "programa político" como estilo constituían una suerte de continuidad con el de Jorge Alessandri (Huneeus 1998, 142). Un punto común era la visión crítica hacia los partidos políticos, ya que "Alessandri había planteado a lo largo de los años 60 y 70 que el único gobierno posible en Chile era aquel que fuera dirigido por un presidente que no fuera interferido por los partidos políticos ni tampoco limitado en el ejercicio de sus facultades por el parlamento" (Huneeus 1998, 142).

\section{LA DERECHA Y LA TECNOCRACIA EN LA DEMOCRACIA POST PINOCHET}

El intento de unificación de la derecha en partido único resultó en la creación de Renovación Nacional (RN) en 1987. Dicho esfuerzo unificador duró hasta 1988, cuando en la elección de la primera directiva nacional se produjo un quiebre, y RN expulsó a Guzmán y Pablo Longueira. El legado pinochetista encontró en la UDI a su principal defensor, mientras que la facción liderada por Andrés Allamand entre 1990 y 1997 en RN promovió una derecha menos comprometida con el legado autoritario. Hernán Büchi, un ex ministro de Hacienda de Pinochet y cercano a los Chicago Boys, fue el abanderado de la derecha en 1989. Sin militancia, su campaña se alejó de los partidos políticos. Esa elección constituyó una derrota para la derecha a manos del candidato de la centroizquierdista Concertación, Patricio Aylwin.

Después de 1990, la UDI y RN evolucionaron en distintas direcciones. RN desarrolló cuadros más heterogéneos, con distintos niveles socioeconómicos, un menor nivel de participación electoral previa (principalmente en elecciones universitarias) y distintas creencias religiosas (Barozet y Aubry 2005; Joignant y Navia 2003). El paso de líderes UDI por cargos clave en el gobierno militar diferenció a esta última de RN (Huneeus 2016; Barozet y Aubry 2005). Además, el "uso intensivo de posiciones políticas territoriales ocupadas durante la dictadura: alcaldes designados, seremis, gobernadores" (Joignant y Navia 2003, 155) le entregó a la UDI una experiencia política notable a sus 
dirigentes, fortaleciendo su capacidad política y electoral una vez en democracia.

En RN hay una baja institucionalización, acompañada por fuertes rasgos de personalismo, pero también con una "gran capacidad de sobrevivencia, resistiendo a la voluntad hegemónica de la UDI” (Barozet y Aubry 2005, 189). RN se ha caracterizado por ser un partido pluralista y pragmático, con diversidad de corrientes, en la que a menudo se han confrontado "duros" o "tradicionales" (más cercanos al legado institucional de Pinochet) con "blandos" o "liberales" (proclives a una derecha democrática) (Barozet y Aubry 2005, 176).

El crecimiento electoral de la UDI hizo que RN dejara de ser el partido mayoritario de la derecha, como muestra el cuadro 3. En la elección presidencial de 1999, el UDI Joaquín Lavín alcanzó el 47,5 por ciento, forzando a la Concertación a una segunda vuelta, y dando inicio a la hegemonía electoral de la UDI. Después de su derrota, Lavín buscó posicionarse para la elección de 2005 como alcalde de la comuna de Santiago, privilegiando un discurso tecnocrático, que si bien no rechazaba a los partidos, los relegaba a un segundo plano.

Cuadro 3. REPRESENTACIÓN DE RN Y UDI EN LA CÁMARA DE DIPUTADOS, 19892013

\begin{tabular}{|c|c|c|c|c|}
\hline Elección & $\%$ de votos & Escaños & $\%$ de votos & Escaños \\
\hline & \multicolumn{2}{|c|}{$\mathrm{RN}$} & \multicolumn{2}{|c|}{ UDI } \\
\hline 1989 & 18,2 & 33 & 9,8 & 11 \\
\hline 1993 & 16,3 & 30 & 12,1 & 15 \\
\hline 1997 & 16,7 & 25 & 14,4 & 17 \\
\hline 2001 & 13,7 & 22 & 25,1 & 31 \\
\hline 2005 & 14,1 & 19 & 22,3 & 33 \\
\hline 2009 & 17,8 & 18 & 23,1 & 37 \\
\hline 2013 & 14,9 & 19 & 18,9 & 29 \\
\hline
\end{tabular}

Fuente: Elaboración de los autores con datos del Servel.

Hacia 2005, la popularidad de Lavín comenzó a caer a la par de una subida en la popularidad del gobierno de la Concertación. Sorpresivamente, a comienzos de 2005, RN proclamó como candidato presidencial a Sebastián Piñera, un empresario y ex senador (1990-1998) 
que, aunque militaba en RN, también promovía una imagen de eficiente gestor, en contraste con la percepción de políticos de carrera. Al final, la derecha se presentó con dos candidatos: Lavín y Piñera. Después de pasar a segunda vuelta y ser derrotado por Bachelet, Piñera quedó posicionado como el candidato de la derecha para 2009. La irrupción de Piñera en 2005 puede entenderse como una "rebelión contra la hegemonía de los gremialistas" (Barozet y Aubry 2005, 180). Pero también convenció a la derecha de su fortaleza electoral. Si en 1999 la derecha se convenció de que era posible ganar, la primera vuelta de 2005 permitió a la derecha sumar 48,5 por ciento, con Piñera ( 25,2 por ciento) y Lavín $(23,3$ por ciento), superando el 46 de la candidata de la Concertación.

\section{EL GOBIERNO DE PIÑERA}

En una reñida elección, que lo enfrentó a tres candidatos provenientes del mundo de la Concertación, Piñera logró imponerse en la segunda vuelta de 2009. Su triunfo validó a una generación que lideró a RN y a la UDI. Esta suerte de victoria en la "última oportunidad" para la generación fraguada en la lógica de la Unidad Popular / Dictadura atenuó los ánimos de renovación y reemplazo dentro de la derecha (Allamand y Cubillos 2010; Bellolio 2013).

El gobierno de Piñera se encuentra marcado por su compleja relación, si no distancia, con los partidos políticos oficialistas. Esta distancia es descrita por Varas (2014) como parte de una estrategia para conformar una nueva derecha que superara la base de apoyo de los partidos oficialistas. El terremoto de febrero de 2010 también forzó al gobierno a modificar su hoja de ruta. La irrupción de conflictos sociales, con las protestas estudiantiles de 2011 y los conflictos regionales, complicaron la labor del ejecutivo y mermaron su apoyo ciudadano.

El gabinete inicial de Piñera constituía un "reflejo" del propio presidente y su trayectoria, aunque marcado por un escaso respaldo político (Varas 2014). Al analizar la trayectoria de Piñera, Dávila (2011) lo caracteriza como un empresario - a pesar de su rol como presidente de RN y su paso por el Senado entre 1990 y 1998-, lo que sin duda influyó a la hora de prescindir de los partidos en la conformación de su primer gabinete. En palabras de Dávila: "El liderazgo del actual mandatario no proviene de su trayectoria política dentro de una corriente determinada" $(2011,41)$. 
Los centros de estudio ligados a la Alianza actuaron como base de reclutamiento. María Luisa Brahm, del Instituto Libertad (IL), Cristián Larroulet, de Libertad y Desarrollo (LyD), y Miguel Flores, de la Fundación Jaime Guzmán (FJG), fueron los encargados de convocar a profesionales para el gabinete, relegando a los partidos políticos a un segundo plano y remarcando el carácter tecnocrático del gabinete inicial. Una muestra de esto es que los ministros Cristián Larroulet (Segpres), Ena von Baer (Segegob), Felipe Larraín (Hacienda), Juan Andrés Fontaine (Economía), Felipe Kast (Desarrollo Social), Felipe Morandé (Transportes), Ricardo Raineri (Energía), y los subsecretarios Tomás Flores (Economía), Gloria Hutt (Transportes), Augusto Iglesias (Trabajo), Nicolás Bar (Cultura), además de la directora de Presupuestos, Rosanna Costa, habían formado parte del think tank Libertad y Desarrollo (LyD) antes de sumarse al gobierno.

Al describir los elencos tecnocráticos del gabinete de Piñera, Silva (2010b) plantea que cuentan con "una serie de particularidades en términos de formación universitaria, trayectoria profesional y origen social, que diferencian visiblemente de lo que fue la tecnocracia concertacionista" (Silva 2010b, 239). Un ejemplo de esto es que, en el gabinete inicial, 14 de los 22 ministros eran ingenieros comerciales o civiles de profesión, principalmente de la Pontificia Universidad Católica. Además, "muchos de ellos son propietarios de empresas o se desempeñaban como gerentes generales de grandes consorcios industriales y comerciales" (Silva 2010b, 250). Estos atributos alimentaron las comparaciones con el gobierno de los gerentes de Jorge Alessandri, dadas las estrechas relaciones con el mundo de los negocios de los miembros de ambos gabinetes.

La poca sintonía del gobierno con los partidos oficialistas despertó críticas de los propios adherentes de Piñera. El senador UDI Pablo Longueira declaraba en 2011: "Falta construir un relato" (Radio Cooperativa 2011). Ese "relato" puede ser entendido como un mecanismo para simplificar ideas o situaciones complejas (Funk 2011), para entender el mundo y dotarlo de significado (White 1980), el cual surge como construcciones a partir de la acción política (Shenhav 2006). El gobierno redujo su relato inicial a la obsesión por la gestión, dejando escaso margen para la doctrina de derecha (Funk 2011). Urbina y Ortúzar (2012) plantean que la carencia de una guía política, basada en principios, que 
le indicara, por ejemplo, qué era justo y bueno para la sociedad, imposibilitó al gobierno para enfrentar el discurso de los estudiantes en el plano de los principios (Urbina y Ortúzar 2012, 15). El foco en las cifras macroeconómicas y la eficiencia profundizó el debate sobre la carencia de relato. Adicionalmente, la inexperiencia de los ministros en el primer gabinete de Piñera fue asociada a la dificultad de la gente para identificarse con el gobierno.

En enero de 2011, un cambio de gabinete produjo la salida del ministro de Defensa, el ex PDC Jaime Ravinet, y la incorporación de los senadores Andrés Allamand (RN) y Evelyn Matthei (UDI). Un analista del sector declaró que "el diseño (inicial) naufragó al poco tiempo. Se hizo un lugar común criticar a La Moneda por su falta de roce político y diversas voces se levantaron para exigir más tonelaje y experiencia" (Bellolio 2013, 35). El ingreso de Allamand y Matthei al gabinete, sumado al posterior ingreso de los senadores UDI Pablo Longueira y Andrés Chadwick el 18 de julio de 2011 constituyen un triunfo de los partidos políticos ante la baja aprobación gubernamental. A partir de agosto de 2011, la llegada de estos cuatro nuevos ministros coincidió con un quiebre en la tendencia a la baja de la aprobación del gobierno, como muestra la figura 2. Después de alcanzar su punto más bajo en mayo de 2012, la aprobación de Piñera comenzó una lenta pero sostenida recuperación.

Los distintos conflictos sociales como las protestas estudiantiles de 2011 y los conflictos regionales en Aysén y Freirina mermaron el apoyo alcanzado en octubre de 2010, a partir del rescate de los 33 mineros de Atacama. Con niveles mínimos de apoyo ciudadano, el oficialismo enfrentó las elecciones municipales de octubre de 2012. El resultado fue desastroso para la derecha, dejando en entredicho tanto al gobierno como a los partidos políticos que sustentaron la labor oficialista: "La Alianza perdió en todo tipo de indicadores: número de alcaldes, votación, población gobernada y municipalidades emblemáticas, como Santiago, Providencia y Concepción" (Varas 2014, 239).

La tensión luego se centró en las elecciones legislativas y presidenciales, que se iniciaron con las primarias del 30 de junio de 2013. Las cartas oficialistas para las primarias fueron el ministro de Defensa y ex senador RN, Andrés Allamand, y el ministro de Obras Públicas, Laurence Golborne, quien se convirtió en el abanderado de la UDI. 
Allamand y Golborne dejaron el gabinete el 5 de noviembre de 2012. Allamand, que encarnaba la figura de hombre de partido, tuvo un activo rol en la transición al promover la democracia de los acuerdos, caracterizada por una oposición colaborativa. Luego Allamand consolidó su carrera como líder en RN desde y fuera del Congreso. Por su parte, Golborne se desempeñó como ejecutivo de grandes empresas de retail hasta que Piñera lo nombró en su primer gabinete. Como ministro de Minería, fue protagonista del rescate de los 33 mineros en 2010, cuestión que lo catapultó a la categoría de presidenciable. Pero dos meses antes de la elección primaria del 30 de junio, Golborne declinó su candidatura producto de cuestionamientos sobre sus inversiones privadas. Golborne fue reemplazado por el ministro de Economía y líder indiscutido UDI, Pablo Longueira.

Aunque las primarias presidenciales tuvieron una participación superior a lo esperado, en las primarias de la Alianza, sólo votaron 800 mil personas, mientras que en las de la Concertación (ahora llamada Nueva Mayoría) votaron casi 2 millones. Longueira obtuvo la victoria con 415.087 votos (51,37 por ciento) por sobre los 392.915 votos (48,63 por ciento) de Allamand.

El 17 de julio, dos semanas después de las primarias, producto de una depresión, Longueira renunció a la nominación presidencial. En un escenario de profundo pesimismo, la UDI nominó a la entonces ministra Evelyn Matthei como candidata, después de una compleja negociación con RN, que aspiraba a que el nominado fuera el propio Allamand. En una arena con nueve candidatos presidenciales, Matthei logró la votación más baja para la derecha desde el retorno de la democracia, alcanzando sólo el 25 por ciento en la primera vuelta presidencial de noviembre de 2013. En la segunda vuelta, Matthei (37,8 por ciento) fue ampliamente derrotada por Bachelet (62,2 por ciento).

\section{LA MILITANCIA POLÍTICA EN EL GABINETE DE PIÑERA}

El cuadro 4 muestra el elenco ministerial durante el cuatrienio de Piñera. Figuran en negritas los ministros que tenían militancia política al asumir sus carteras. Ya que buscamos mostrar la densidad partidista, más que detallar los distintos cambios de gabinete, no se incorporan casos de ministros que estuvieron por muy poco tiempo en el poder (como 
Cuadro 4. COMPOSICIÓN DEL GABINETE DE SEBASTIÁN PIÑERA, 2010-2014

\begin{tabular}{|c|c|c|c|c|}
\hline Ministerio & 2010 & 2011 & 2012 & 2013 \\
\hline Interior & $\begin{array}{l}\text { Rodrigo } \\
\text { Hinzpeter }\end{array}$ & $\begin{array}{l}\text { Rodrigo } \\
\text { Hinzpeter }\end{array}$ & $\begin{array}{l}\text { Rodrigo } \\
\text { Hinzpeter }\end{array}$ & Andrés Chadwick \\
\hline RR.EE. & Alfredo Moreno & Alfredo Moreno & Alfredo Moreno & Alfredo Moreno \\
\hline Defensa & Jaime Ravinet & Andrés Allamand & Andrés Allamand & Rodrigo Hinzpeter \\
\hline Hacienda & Felipe Larrain & Felipe Larrain & Felipe Larraín & Felipe Larrain \\
\hline Segpres & Cristián Larroulet & Cristián Larroulet & Cristián Larroulet & Cristián Larroulet \\
\hline Segegob & Ena von Baer & $\begin{array}{c}\text { von Baer/ } \\
\text { Andrés Chadwick }\end{array}$ & Andrés Chadwick & Cecilia Pérez \\
\hline Economía & Juan A. Fontaine & $\begin{array}{c}\text { Juan A. Fontaine/ } \\
\text { Pablo Longueira }\end{array}$ & Pablo Longueira & $\begin{array}{c}\text { Longueira/ } \\
\text { Félix de Vicente }\end{array}$ \\
\hline Planificación* & Felipe Kast & $\begin{array}{l}\text { Felipe Kast/ } \\
\text { Joaquín Lavin }\end{array}$ & Joaquín Lavín & $\begin{array}{l}\text { Lavín/Bruno } \\
\text { Baranda }\end{array}$ \\
\hline Educación & Joaquín Lavín & $\begin{array}{l}\text { Joaquín Lavin/ } \\
\text { Felipe Bulnes }\end{array}$ & Harald Beyer & Carolina Schmidt \\
\hline Justicia & Felipe Bulnes & $\begin{array}{c}\text { Bulnes/ } \\
\text { Teodoro Ribera }\end{array}$ & Teodoro Ribera & Patricia Pérez \\
\hline Trabajo & Camila Merino & Evelyn Matthei & Evelyn Matthei & $\begin{array}{l}\text { Juan Carlos } \\
\text { Jobet }\end{array}$ \\
\hline Obras Públicas & H. de Solminihac & $\begin{array}{l}\text { H. de Solminihac/ } \\
\text { Laurence Golborne }\end{array}$ & $\begin{array}{l}\text { Laurence } \\
\text { Golborne }\end{array}$ & Loreto Silva \\
\hline Salud & Jaime Mañalich & Jaime Mañalich & Jaime Mañalich & Jaime Mañalich \\
\hline Vivienda & Magdalena Matte & Rodrigo Pérez & Rodrigo Pérez & Rodrigo Pérez \\
\hline Agricultura & José A. Galilea & José A. Galilea & Luis Mayol & Luis Mayol \\
\hline Transportes & Felipe Morandé & Pedro Errázuriz & Pedro Errázuriz & Pedro Errázuriz \\
\hline B. Nacionales & Catalina Parot & Catalina Parot & Catalina Parot & Rodrigo Pérez \\
\hline Energía & Ricardo Rainieri & $\begin{array}{c}\text { Golborne/ } \\
\text { Rodrigo Álvarez }\end{array}$ & $\begin{array}{l}\text { Rodrigo Álvarez/ } \\
\text { Jorge Bunster }\end{array}$ & Jorge Bunster \\
\hline Minería & $\begin{array}{l}\text { Laurence } \\
\text { Golborne }\end{array}$ & $\begin{array}{l}\text { Laurence Golborne/ } \\
\text { H. de Solminihac }\end{array}$ & H. de Solminihac & H. de Solminihac \\
\hline Sernam & Carolina Schmidt & Carolina Schmidt & Carolina Schmidt & Loreto Seguel \\
\hline Cultura & Luciano Cruz-Coke & Luciano Cruz-Coke & Luciano Cruz-Coke & Roberto Ampuero \\
\hline Medio Ambiente & M. Ignacia Benítez & M. Ignacia Benítez & M. Ignacia Benítez & M. Ignacia Benítez \\
\hline Militantes & 8 & 15 & 11 & 10 \\
\hline Total ministros & 22 & 30 & 22 & 24 \\
\hline$\%$ de militantes & 36,3 & 50 & 50 & 41,6 \\
\hline
\end{tabular}

Nota: En negrita se marcan los ministros con militancia política en partidos de la coalición gobernante.

Fuente: Autores con datos del gobierno de Chile. 
el titular de Energía Fernando Echeverría, quien estuvo sólo cuatro días en su cargo).

En su gabinete inicial, Piñera nombró a 8 ministros con militancia, 4 RN y 4 UDI. En 2011, con los cambios realizados en enero y julio, los militantes ascendieron a 12: 6 RN y 6 UDI. Al año siguiente, el número bajó a 10, con la salida del UDI Rodrigo Álvarez de Energía y Felipe Bulnes de Educación. Finalmente, en 2013, volvió a bajar a 8: 5 RN y 3 UDI. En síntesis, entre 2011 y 2012 hubo mayor presencia de ministros militantes, con 12 y 10 respectivamente, mientras que en 2010 y 2013 solo se contabilizaron 8.

La presencia de más ministros con militancia en los años más conflictivos - 2011 y 2012 - muestra que Piñera recurrió a la militancia cuando su gobierno tuvo problemas. El aumento en la densidad de militancia coincidió con la estabilización de la aprobación presidencial. Hacia el final del gobierno, cuando algunos militantes dejaron el gabinete para iniciar sus propias aventuras electorales, Piñera volvió a nombrar ministros no militantes. La incorporación al gabinete de Piñera de individuos que contaban con trayectorias intensamente vinculadas a los partidos políticos de la derecha contribuyó para romper la tendencia a la baja de la aprobación presidencial y para estabilizar el apoyo al gobierno.

Con todo, el cuadro 4 deja en evidencia la escasa militancia en el elenco de ministros durante el cuatrienio aliancista. No es novedoso contrastar esta situación con la trayectoria política de la derecha chilena. El gobierno de Alessandri —último gobierno de derecha elegido democráticamente previo a Piñera - recurrió a gerentes y empresarios para poblar el gabinete. En el gobierno de Piñera, la derecha volvió a vivir esa asepsia política, en la que sus candidatos presidenciales y principales líderes provienen de la tecnocracia o desde la independencia política.

Como contraste, el cuadro 5 muestra la composición del gabinete del primer gobierno de Bachelet. Los ministros en negritas no cuentan con militancia política previa. En 2006, de los 22 ministros, sólo 2 no tenían militancia. En 2007 hubo 2 sin militancia, y en los dos años siguientes, el número de ministros sin militancia bajó a 1. El gabinete de Bachelet siempre estuvo dominado por ministros con militancia partidista, lo que presumiblemente contribuyó a tener una mejor relación con los partidos oficialistas. Los cuadros 4 y 5 confirman las diferencias en la vinculación de los gobiernos de Bachelet y Piñera con los partidos 
Cuadro 5. COMPOSICIÓN DEL GABINETE DE MICHELLE BACHELET, 2006-2010

\begin{tabular}{|c|c|c|c|c|}
\hline Ministerio & 2006 & 2007 & 2008 & 2009 \\
\hline Interior & $\begin{array}{l}\text { Andrés Zaldivar/ } \\
\text { Belisario Velasco }\end{array}$ & Belisario Velasco & $\begin{array}{l}\text { Edmundo } \\
\text { Pérez Y. }\end{array}$ & $\begin{array}{l}\text { Edmundo } \\
\text { Pérez Y. }\end{array}$ \\
\hline RREE & Alejandro Foxley & Alejandro Foxley & Alejandro Foxley & $\begin{array}{l}\text { Mariano } \\
\text { Fernández }\end{array}$ \\
\hline Defensa & Vivianne Blanlot & José Goñi & José Goñi & Francisco Vidal \\
\hline Hacienda & Andrés Velasco & Andrés Velasco & Andrés Velasco & Andrés Velasco \\
\hline SEGPRES & Paulina Veloso & $\begin{array}{c}\text { José A. } \\
\text { Viera-Gallo }\end{array}$ & $\begin{array}{c}\text { José A. } \\
\text { Viera-Gallo }\end{array}$ & $\begin{array}{c}\text { José A. } \\
\text { Viera-Gallo }\end{array}$ \\
\hline SEGEGOB & R. Lagos Weber & Francisco Vidal & Vidal/Carol. Tohá & $\begin{array}{l}\text { Tohá/Pilar } \\
\text { Armanet }\end{array}$ \\
\hline Economía & Ingrid Antonijevic & $\begin{array}{l}\text { Alejandro } \\
\text { Ferreiro }\end{array}$ & Hugo Lavados & Hugo Lavados \\
\hline Planificación & Clarisa Hardy & Clarisa Hardy & Paula Quintana & Paula Quintana \\
\hline Educación & $\begin{array}{c}\text { Martin Zilic/ } \\
\text { Yasna Provoste }\end{array}$ & Yasna Provoste & Mónica Jiménez & Mónica Jiménez \\
\hline Justicia & Isidro Solis & $\begin{array}{c}\text { Carlos } \\
\text { Maldonado }\end{array}$ & $\begin{array}{c}\text { Carlos } \\
\text { Maldonado }\end{array}$ & $\begin{array}{c}\text { Carlos } \\
\text { Maldonado }\end{array}$ \\
\hline Trabajo & Osvaldo Andrade & Osvaldo Andrade & Osvaldo Andrade & Claudia Serrano \\
\hline Obras Públicas & Eduardo Bitran & Eduardo Bitran & Sergio Bitar & Sergio Bitar \\
\hline Salud & M Soledad Barría & M Soledad Barría & M Soledad Barría & Álvaro Erazo \\
\hline Vivienda & Patricia Poblete & Patricia Poblete & Patricia Poblete & Patricia Poblete \\
\hline Agricultura & Álvaro Rojas & Álvaro Rojas & Marigen Hornkohl & Marigen Hornkohl \\
\hline Transportes & Sergio Espejo & René Cortázar & René Cortázar & René Cortázar \\
\hline B. Nacionales & Romy Schmidt & Romy Schmidt & Romy Schmidt & Romy Schmidt \\
\hline Energía & Karen Poniachik & Marcelo Tokman & Marcelo Tokman & Marcelo Tokman \\
\hline Minería & Karen Poniachik & Karen Poniachik & $\begin{array}{l}\text { Santiago } \\
\text { González }\end{array}$ & $\begin{array}{l}\text { Santiago } \\
\text { González }\end{array}$ \\
\hline SERNAM & Laura Albornoz & Laura Albornoz & Laura Albornoz & Laura Albornoz \\
\hline Cultura & Paulina Urrutia & Paulina Urrutia & Paulina Urrutia & Paulina Urrutia \\
\hline Militantes & 20 & 19 & 21 & 21 \\
\hline Total ministros & 22 & 21 & 22 & 22 \\
\hline$\%$ de ministros & 91 & 90,5 & 95,5 & 95,5 \\
\hline
\end{tabular}

Nota: En negrita se marcan los ministros sin militancia política.

Fuente: Autores con datos del gobierno de Chile. 
Figura 1. PROMEDIO DE DENSIDAD PARTIDISTA (IDP) DE MIEMBROS DE LOS GABINETES DE BACHELET Y PIÑERA, 2006-2014

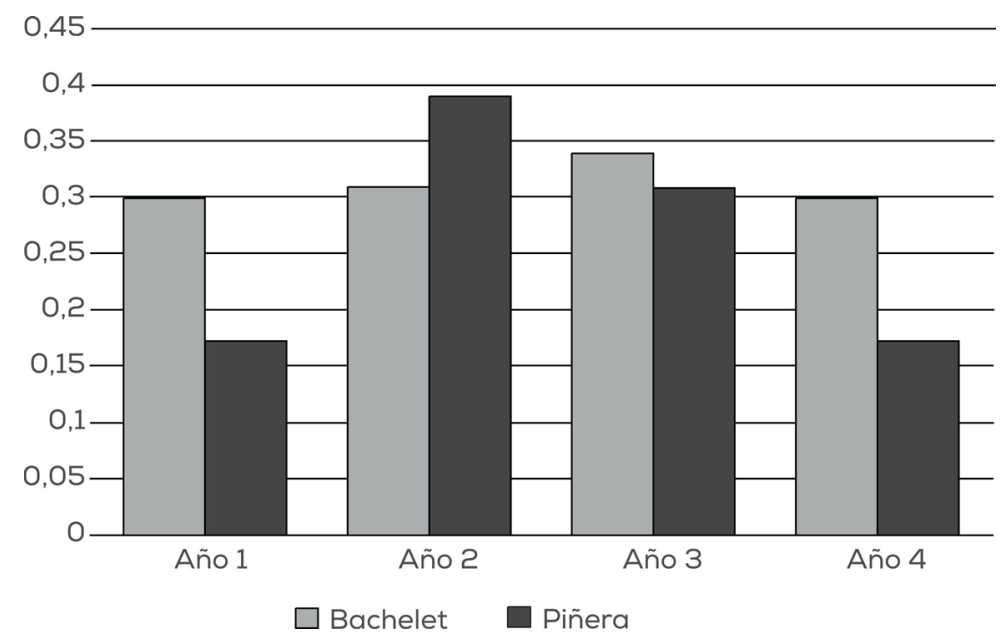

Fuente: Autores con datos recopilados de diversas fuentes de acceso público.

que forman sus respectivas coaliciones en el espacio de influencia que constituye el gabinete.

La figura 1 muestra la densidad de militancia promedio de los miembros de los gabinetes de Bachelet y Piñera en cada año de sus respectivos gobiernos. Hubo menos varianza en el IDP de los gabinetes de Bachelet. En el gobierno de Piñera, el IDP fue especialmente bajo en el primer y último año. El mayor IDP se produjo en el segundo año. De hecho, el IDP del gabinete en el segundo año de Piñera fue superior al IDP del gabinete del segundo año de Bachelet. Pero en promedio, Bachelet tuvo un IDP más alto que el de Piñera. Mientras el de Piñera fluctuó entre 0,17 y 0,39, el de Bachelet se movió en un rango de 0,30 y 0,34.

\section{IDP Y APROBACIÓN PRESIDENCIAL}

Contrastamos el IDP con la aprobación presidencial de la encuesta Adimark entre marzo de 2010 y febrero de $2014 .{ }^{1}$ La figura 2 muestra

${ }^{1}$ Entre octubre de 2012 y enero de 2013, aduciendo razones metodológicas, Adimark no realizó su encuesta. Usamos los datos de septiembre de 2012 para esos meses. 
la varianza en el IDP y la aprobación presidencial. A medida que avanzó el gobierno, la aprobación presidencial fue cayendo, hasta principios de 2012. El gobierno respondió con dos cambios de gabinete, en enero y julio de 2011. Si bien su aprobación siguió cayendo después del primer cambio de gabinete en enero de 2011, ese cambio sólo incluyó cuatro carteras. En dos de ellas, el remplazante tenía la misma nula densidad de militancia partidista (Errázuriz por Morandé, en Transportes, y Golborne por Raineri en Energía). En los otros dos casos — Trabajo y Defensa-, el ingreso de los ministros Matthei y Allamand constituyó un alza en el IDP, en tanto ambos remplazan a ministros con menor IDP. Pero en el promedio del gabinete, el IDP pasó sólo de 0,17 a 0,24. En cambio, después del cambio de gabinete en julio de 2011, el IDP llegó a 0,39, superior incluso al que tuvo Bachelet en promedio en sus cuatro años de gobierno.

El mayor IDP del gabinete después de julio de 2011 coincidió con la estabilización en la aprobación presidencial e incluso con una cierta

Figura 2. DENSIDAD PARTIDISTA (IDP) EN EL GABINETE DE PIÑERA Y APROBACIÓN PRESIDENCIAL, 2010-2014

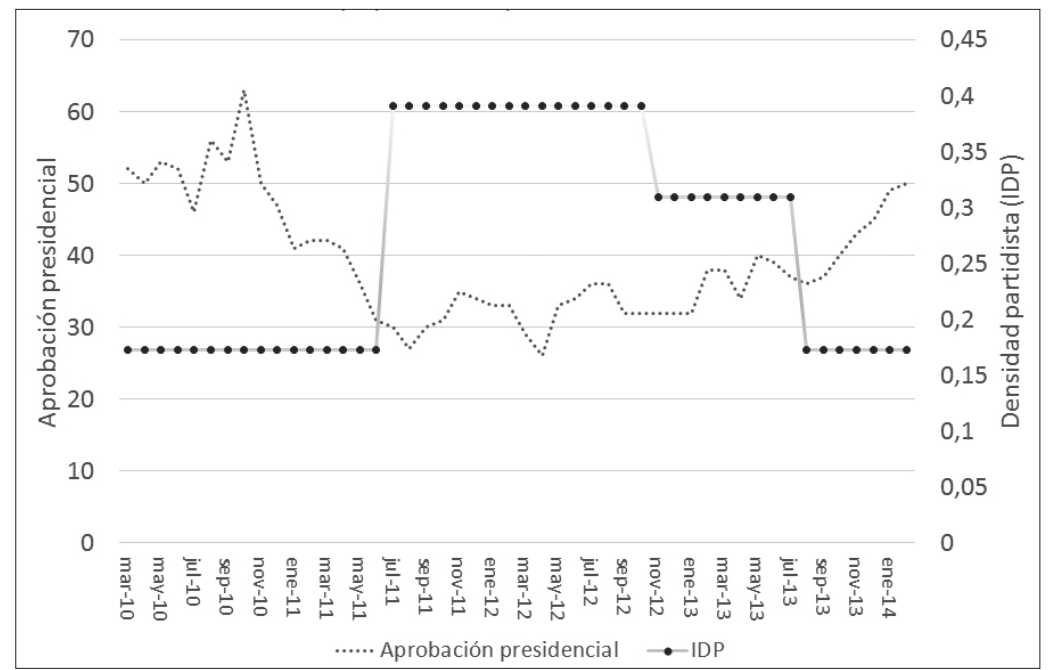

Fuente: Autores con datos de Adimark y propios. 
mejora hacia fines de 2012. La aprobación presidencial comenzó a caer a fines de 2010 y tocó fondo en abril de 2012, cuando llegó a 26 por ciento. A partir de entonces, y coincidente con el cambio de gabinete que hizo subir el IDP, la aprobación presidencial se estabilizó y comenzó a subir hasta llegar a 36 por ciento en agosto de 2012.

En suma, el IDP aumentó con fuerza cuando se incorporaron al gabinete los senadores Allamand, Matthei, Longueira y Chadwick. A partir de entonces, el gobierno de Piñera inició un lento pero sostenido repunte en las encuestas. Después de la derrota en la elección municipal de 2012, en el mes de noviembre, el desafío de la elección presidencial propició la salida del gabinete de los candidatos presidenciales, Golborne y Allamand, y de sus jefes de campaña, Lavín y Luciano CruzCoke, lo que hizo bajar el IDP. Posteriormente, la salida de Longueira y Matthei, ambos para asumir una candidatura presidencial, dejó al gabinete sin líderes políticos de los partidos de la Alianza, desencadenando una fuerte baja en el IDP, que en julio de 2013 volvió al nivel del gabinete inicial.

Aunque en el cuatrienio de Piñera los conflictos políticos fueron una constante, la llegada de senadores aliancistas al gabinete ayudó a reducirlos, contribuyendo a revertir la caída en aprobación presidencial. Visualmente, la figura 2 muestra que el aumento en IDP está positivamente relacionado con una mejora en la aprobación presidencial después de la caída que se observó a fines de 2010, al finalizar la luna de miel presidencial. Ya que el IDP durante el cuatrienio de Bachelet no tuvo mayor varianza - manteniéndose alto durante todo el periodo-, no estimamos la relación del IDP en su gobierno con la aprobación presidencial, en tanto la variable independiente no varió durante el periodo.

La figura 3 muestra el IDP de los ministros y la varianza mensual de la aprobación presidencial, retrasada un mes. Esto, porque el efecto de un cambio de gabinete - que aumente o disminuya el IDP - no se verá inmediatamente reflejado en cambios en la aprobación presidencial. De ahí que estimamos también la relación retrasada (lagged) de IDP y el cambio en aprobación presidencial entre un mes y otro. Al correlacionar el IDP del mes anterior con la varianza en aprobación presidencial (del mes anterior menos la del mes ac- 
Figura 3. IDP DE MINISTROS (LAGGED) Y VARIANZA MENSUAL EN APROBACIÓN PRESIDENCIAL, 2010-2014

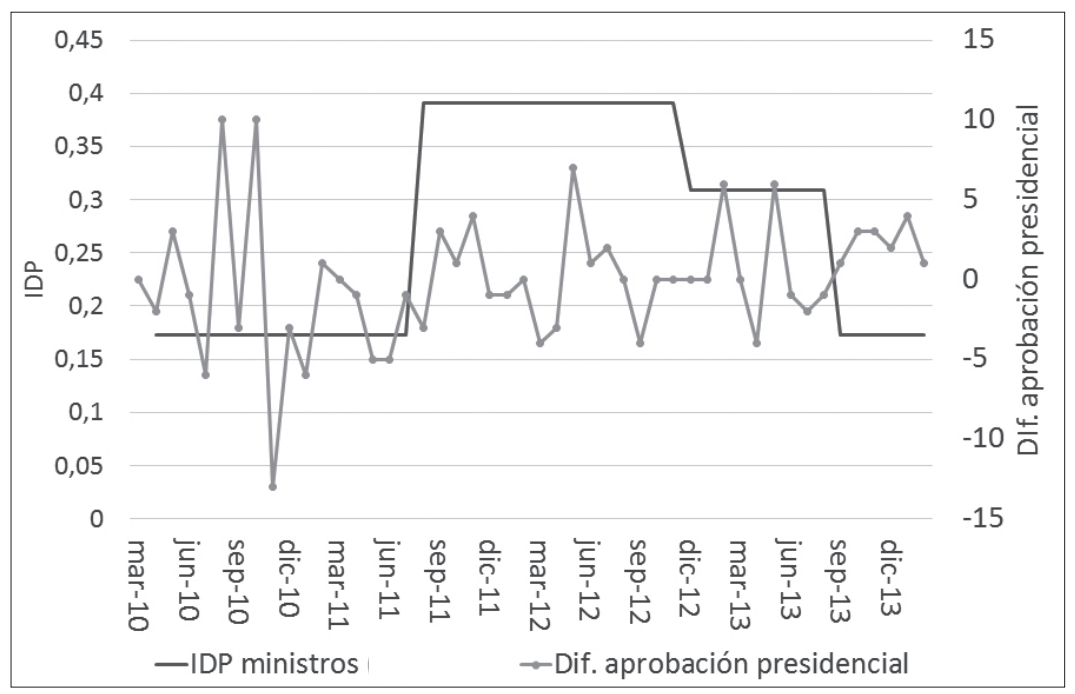

tual), esa correlación da un valor de 0,062. Esto quiere decir que cuando aumentó el IDP, la aprobación presidencial también experimentó una mejora.

La figura 4 muestra el IDP en los subsecretarios y la varianza mensual de la aprobación presidencial, retrasada también por un mes. La correlación entre el IDP de los subsecretarios y los valores mensuales de aprobación es de 0,902 , confirmando una relación positiva entre un aumento en la densidad partidista y mejoras en la aprobación presidencial.

Hacia 2013, el IDP de los ministros volvió a disminuir, cayendo a 0,30 hacia fines de 2012 y a 0,17 a mediados de 2013 , cuando varios ministros dejaron el gabinete para asumir candidaturas en las elecciones de noviembre. Ya que el resultado de la elección presidencial y legislativa se explica, desde una mirada retrospectiva, por lo que ocurrió durante todo el cuatrienio, esta caída en IDP no empeoró necesariamente lo que fue un IDP bajo durante todo el periodo. Si bien el IDP en el gabinete de Bachelet también fue bajo, la gran mayoría de los ministros de Bachelet tenían algo de experiencia como militantes, mientras que en el de Piñera, los militantes eran una excepción. 
Figura 4. IDP EN SUBSECRETARIOS (LAGGED) Y VARIANZA MENSUAL EN APROBACIÓN PRESIDENCIAL, 2010-2014

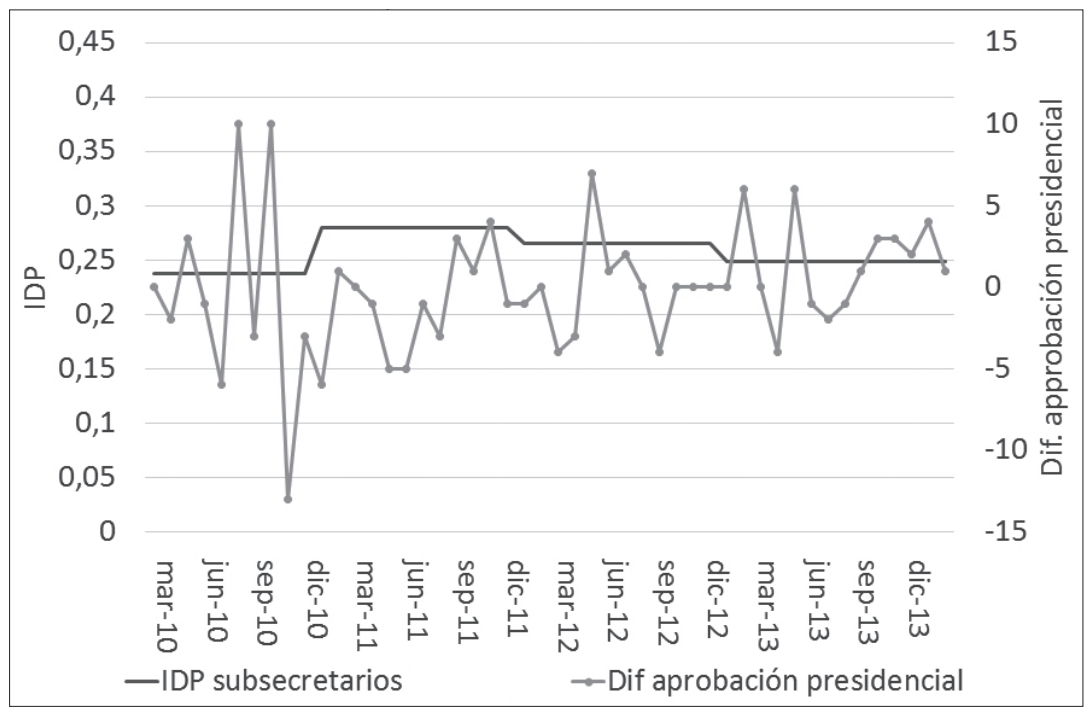

Fuente: Autores con datos de Adimark y propios.

\section{CONCLUSIONES}

Hemos planteado tres criterios para evaluar si un gobierno es exitoso: si la aprobación del gobierno supera el 50 por ciento durante el cuatrienio, si la coalición oficialista es capaz de retener el gobierno y, finalmente, si la coalición oficialista gana las elecciones legislativas al fin del periodo. Desde 1990 en adelante, el gobierno de Piñera fue el único que no logró cumplir ninguno de dichos criterios. Ampliando la lógica del voto retrospectivo, sugerimos que los votantes no sólo evalúan las condiciones de la economía para premiar o castigar a la coalición incumbente, sino que las variables políticas - en específico, la capacidad del ejecutivo para formar un gabinete que refleje la diversidad de los partidos que forman la coalición - también influyen en su determinación del voto. El bajo IDP perjudicó la evaluación de la ciudadanía sobre el gobierno de Piñera, contribuyendo a la derrota de la coalición oficialista en las elecciones presidenciales y legislativas de 2013.

Explicamos la derrota de la derecha en 2013 a partir del concepto de Índice de Densidad de Partidista (IDP), compuesto por cinco con- 
diciones dicotómicas: la militancia partidista, haber presentado una candidatura anterior, ostentar el cargo de concejal o alcalde previamente, ostentar el cargo de legislador previamente y haber ejercido como miembro directiva nacional de un partido político. Nuestra hipótesis es que el bajo IDP en el gabinete de Piñera contribuyó a su baja aprobación presidencial y a los malos resultados electorales para su coalición al finalizar el gobierno en 2013.

La composición del gabinete de gobierno de Piñera evidenció un sesgo a favor de los tecnócratas y contra los militantes. El IDP del gabinete de Piñera refleja una valoración menor por la militancia partidista que la observada en el gobierno predecesor de la Concertación. A su vez, cuando el IDP del gabinete aumentó, el gobierno de Piñera fue capaz de revertir su baja aprobación presidencial. Contar con un gabinete con militantes — una mayor densidad de IDP — contribuyó a incrementar la aprobación del gobierno, aunque no pudo evitar la derrota electoral de 2013. La designación de Allamand, Matthei, Longueira y Chadwick como miembros del gabinete presidencial ayudó a frenar la caída en la aprobación presidencial durante el gobierno de Piñera. En julio de 2011, la caída en la aprobación se detuvo y comenzó un lento pero sostenido repunte en las encuestas de opinión que fue de mayo del 2012 hasta el término del mandato. Entre julio 2011 y noviembre 2012 se registró el nivel más alto del IDP durante el cuatrienio aliancista, que fue cuando coincidieron los cuatro ex senadores en el gabinete.

Si bien no resulta novedoso que el reclutamiento de los principales cargos del gobierno al comienzo de la administración de Piñera estuviera cargado de agentes con escasa densidad de militancia, la incorporación al gabinete ministerial de dirigentes con mayor densidad de militancia contribuyó a estabilizar al gobierno cuando atravesaba por su peor momento y coincidió con el freno en la caída sistemática en la aprobación presidencial.

La relación de la derecha chilena con la militancia política ha estado marcada históricamente por la desconfianza. Gustavo Ross, candidato presidencial de la derecha en 1938, encarnó la figura del tecnócrataapolítico. Después, Jorge Alessandri, candidato en 1958; Hernán Büchi, en 1989; Joaquín Lavín, en 1999 y 2005; y finalmente Sebastián Piñera, en 2005 y 2009, representaron también un liderazgo legitimado más por sus trayectorias profesionales que por su desempeño político. La elec- 
ción presidencial de 2013 fue una dura derrota para la derecha chilena. Luego del triunfo en 2009 y el retorno de la derecha a La Moneda después de 50 años, el gobierno de Piñera no fue capaz de retener el poder finalizado el cuatrienio y su lista de candidatos al legislativo disminuyó fuertemente su votación respecto a 2009, a pesar de las favorables condiciones de la economía.

\section{REFERENCIAS}

Alemán, E. \& G. Tsebelis. 2012. "Partidos políticos y coaliciones de gobierno en las Américas". Política, Revista de Ciencia Política 50 (2): 5-32.

Allamand, A. 1999. La travesía del desierto. Santiago: Aguilar.

Allamand, A. \& M. Cubillos. 2010. La estrella y el arco iris. Santiago: Aguilar.

Altman, D. \& R. Castiglioni. 2009. "Gabinetes ministeriales y reformas estructurales en América Latina, 1985-2000". Revista Uruguaya de Ciencia Politica 18 (1): 15-39.

Amorim Neto, O. 2006. "The Presidential Calculus: Executive Policy Making and Cabinet Formation in the Americas". Comparative Political Studies 39 (4): 415-440.

Aninat, C., J. Londregan, P. Navia \& J. Vial. 2011. "Juego político cooperativo. Instituciones, procesos políticos, y características de las políticas públicas en Chile". En El juego político en América Latina: ¿Cómo se deciden las políticas públicas?, editado por C. Scartascini, P. Spiller, E. Stein y M. Tommasi, 161-206. Bogotá: Planeta.

Avendaño, O. \& M. Dávila. 2012: "Rotación ministerial y estabilidad coalicional en Chile, 1990-2010”. Politica. Revista de Ciencia Política 50 (2): 87.

Barozet, E. \& M. Aubry. 2005. "De las reformas internas a la candidatura presidencial autónoma: los nuevos caminos institucionales de Renovación Nacional". Política. Revista de Ciencia Política 45: 165-196.

Bartels, L. M. 2011. "The Study of Electoral Behavior". The Oxford Handbook of American Elections and Political Behavior, editado por J. E. Leighley. New York: Oxford University Press.

Bellolio, C. 2013. Renovación y reemplazo. Santiago: Planeta.

Boeninger, E. 2014. Gobernabilidad: lecciones de la experiencia. Santiago: Uqbar editores.

Carey, J. \& P. Siavelis. 2003. "El 'seguro' para los subcampeones electorales y la supervivencia de la Concertación”. Estudios Públicos 90: 5-27.

Correa, S. 2011. Con las riendas del poder. Santiago: Ediciones De Bolsillo.

Cristi, R. 2011. El pensamiento político de Jaime Guzmán (2 ${ }^{\mathrm{a}}$. edición). Santiago: Lom Ediciones. 
Dávila, M. 2011. "Tecnocracia y política en el Chile postautoritario (1990-2010)". En Notables, tecnócratas y mandarines. Elementos de sociología de las elites en Chile (1990-2010), editado por Alfredo Joignant y Pedro Guell. Santiago: Ediciones Universidad Diego Portales.

Delamaza, G. 2011. "Elitismo democrático, líderes civiles y tecnopolítica en la reconfiguración de las élites políticas". En Notables, tecnócratas y mandarines. Elementos de sociología de las elites en Chile (1990-2010), editado por Alfredo Joignant y Pedro Guell. Santiago: Ediciones Universidad Diego Portales.

Domínguez, J. I. 1997. Technopols: Freeing Politics and Markets in Latin America in the 1990s. Pennsylvania: The Pennsylvania State University Press.

Downs, A. 1957. An Economic Theory of Democracy. New York: Harper \& Row.

Duch, R. M. \& R. T. Stevenson. 2008. The Economic Vote. How Political and Economic Institutions Condition Election Results. New York: Cambridge University Press.

Ferejohn, J. 1986. "Incumbent Performance and Electoral Control." Public Choice 50: 5-25.

Figueiredo, A. C. \& F. Limongi. 2000. "Presidential Power, Legislative Organization, and Party Behavior in Brazil". Comparative Politics 32 (2): 151-170.

Funk, R. 2011. "El relato político en el primer año del gobierno de Piñera". Política. Revista de Ciencia Política 49 (2): 151-159.

Gamboa, R., M. Á. López \& J. Baeza. 2013. "La evolución programática de los partidos chilenos 1970-2009: De la polarización al consenso". Revista de Ciencia Política 33 (2): 443-467.

Garretón, M. A. 1994. "La evolución política del régimen militar chileno y los problemas en la transición a la democracia". En Transiciones desde un gobierno autoritario, editado por G. O'Donnell, P. C. Schmitter y L. Whitehead. Barcelona: Editorial Paidós.

González Bustamante, B. 2013. "Factores de acceso y permanencia de la élite política gubernamental en Chile (1990-2010)". Política. Revista de Ciencia Politica 51 (1): 119-153.

Grindle, M. 1977. "Power, Expertise and the 'Tecnico': Suggestions from a Mexican Case Study". The Journal of Politics 39: 399-426.

Guzmán Errázuriz, J. 2008. Escritos personales. Santiago: Fundación Jaime Guzmán.

Huneeus, C. 1973. Movimientos universitarios y generación de elites dirigentes. Santiago: Corporación de Promoción Universitaria.

1998. "Tecnócratas y políticos en un régimen autoritario. Los Odeplan boys y los gremialistas en el Chile de Pinochet". Revista de Ciencia Politica 19 (2): $125-158$

2016. El régimen de Pinochet. Santiago: Taurus.

Joignant, A. 2011. "Tecnócratas, technopols y dirigentes de partido: tipos de agentes y especies de capital en las elites gubernamentales de la Concertación (1990- 
2010)". En Notables, tecnócratas y mandarines. Elementos de sociología de las elites en Chile (1990-2010), editado por Alfredo Joignant y Pedro Guell. 2011. Santiago: Ediciones Universidad Diego Portales.

—. 2012. "Habitus, campo y capital. Elementos para una teoría general del capital político". Revista Mexicana de Sociología 74 (4): 587-618.

Joignant, A. \& P. Navia. 2003. "De la política de individuos a los hombres del partido. Socialización, competencia política y penetración electoral de la UDI (1989-2001)”. Estudios Públicos 89: 130-171.

Laver, M. \& W. B. Hunt. 1992. Policy and Party Competition. New York: Routledge.

Laver, M. \& K. A. Shepsle. 1990. "Coalitions and Cabinet Government". American Political Science Review 84 (3): 873-890.

. 1996. Making and Breaking Governments. Cabinets and Legislators in Parliamentary Democracies. New York: Cambridge University Press.

Moulian, T. \& I. Torres Dujisin. 1988. Discusiones entre honorables: las candidaturas presidenciales de la derecha entre 1938 y 1946. Santiago: Flacso.

Navia, P. \& R. Godoy. 2014. "The Alianza's Quest to Win Power Democratically". En Democratic Chile. The Politics and Policies of a Historic Coalition, 19902010, editado por K. Sehnbruch \& P.M. Siavelis. Boulder: Lynne Rienner Publishers.

Navia, P. \& R. Osorio. 2015. "Una aproximación al estado del voto económico en América Latina”. Política, Revista de Ciencia Política, 53 (1): 7-14.

Olivares, A., J. Baeza \& M. Dávila. 2015. "Los gabinetes ministeriales en la democracia chilena pos 1990: un caso de estabilidad, continuidad histórica y negociación inter-partidaria". Documentos y Aportes en Administración Pública y Gestión Estatal 15 (24): 7-31.

Palacios, C. \& H. Jofré. 2016. "Permanencia de agentes clave en el Centro de Gobierno. El caso chileno (1990-2014)". Enfoques 14 (24): 91-119.

Radio Cooperativa. 2011. "Longueira: 'El Presidente Piñera y el Gobierno no tienen un relato político"'. 11 de abril. http://www.cooperativa.cl/longueiraelpresidente-pinera-y-el-gobierno-no-tienen-un-relato-politico/prontus nots/2011-04-11/005228.html.

Shenhav, S. R. 2006. "Political Narratives and Political Reality". International Political Science Review 27 (3): 245-262.

Siavelis, P. 2000. The President and Congress in Post-Authoritarian Chile: Institutional Constraints to Democratic Consolidation. University Park, PA: Penn State University Press.

- 2009. "Enclaves de la transición y democracia chilena". Revista de Ciencia Política 29 (1): 3-21.

Silva, P. 2010a. "Tecnocracia y gobernabilidad democrática en América Latina”. En Actores y desafios a la convivencia política en América Latina, coordinado por Juany Guzmán León. San José de Costa Rica: Flacso. 
2010b. En el nombre de la razón: Tecnócratas y política en Chile. Santiago: Ediciones Universidad Diego Portales.

Urbina, F. J. \& P. Ortúzar. 2012. Gobernar con principios: Ideas para una nueva derecha. Santiago: Ediciones LyD.

Varas, A. 2014. El gobierno de Piñera (2010-2014). Santiago: Catalonia.

White, H. 1980. "The Value of Narrativity in the Representation of Reality". Critical inquiry 7 (1): 5-27. EP 